\title{
Retraction
}

\section{Retracted: Quasilinear Inner Product Spaces and Hilbert Quasilinear Spaces}

\section{International Journal of Analysis}

Received 8 August 2016; Accepted 8 August 2016

Copyright (C) 2016 International Journal of Analysis. This is an open access article distributed under the Creative Commons Attribution License, which permits unrestricted use, distribution, and reproduction in any medium, provided the original work is properly cited.

At the request of the authors, the article titled "Quasilinear Inner Product Spaces and Hilbert Quasilinear Spaces" [1] has been retracted. The article was found by the authors to contain a number of mathematical errors, undefined expressions, and spelling errors, which mean that the conclusions cannot be relied upon.

\section{References}

[1] H. Bozkurt, S. Çakan, and Y. Yılmaz, "Quasilinear inner product spaces and Hilbert quasilinear spaces," International Journal of Analysis, vol. 2014, Article ID 258389, 7 pages, 2014. 